\title{
Laboratory Properties of Waste PET Plastic-Modified Asphalt Mixes
}

\author{
Nuha Mashaan*D, Amin Chegenizadeh* and Hamid Nikraz \\ Department of Civil Engineering, School of Civil and Mechanical Engineering, Curtin University, \\ Perth 6102, Australia; h.nikraz@curtin.edu.au \\ * Correspondence: nuhasmashaan@postgrad.curtin.edu.au or nuhas.mashaan1@curtin.edu.au (N.M.); \\ amin.chegenizadeh@curtin.edu.au (A.C.)
}

Citation: Mashaan, N.;

Chegenizadeh, A.; Nikraz, H.

Laboratory Properties of Waste PET Plastic-Modified Asphalt Mixes.

Recycling 2021, 6, 49. https://

doi.org/10.3390/recycling6030049

Academic Editors: José Neves, Ana Cristina Freire and Carlos Chastre

Received: 17 May 2021

Accepted: 12 July 2021

Published: 14 July 2021

Publisher's Note: MDPI stays neutral with regard to jurisdictional claims in published maps and institutional affiliations.

Copyright: (c) 2021 by the authors. Licensee MDPI, Basel, Switzerland. This article is an open access article distributed under the terms and conditions of the Creative Commons Attribution (CC BY) license (https:/ / creativecommons.org/licenses/by/ $4.0 /)$.

\begin{abstract}
Commercial polymers have been used in pavement modification for decades; however, a major drawback of these polymers is their high cost. Waste plastic polymers could be used as a sustainable and cost-effective additive for improving asphalt properties, attaining combined environmental-economic benefits. Since 2019, in Australia, trial segments of roads have been built using waste materials, including plastic, requiring that laboratory evaluations first be carried out. This study aims to examine and evaluate the effect of using a domestic waste plastic, polyethylene terephthalate (PET), in modifying C320 bitumen. The assessment of several contents of PET-modified bitumen is carried out in two phases: modified bitumen binders and modified asphalt mixtures. Dynamic shear rheometer (DSR) and rolling thin film oven tests (RTFOT) were utilised to investigate the engineering properties and visco-elastic behaviour of plastic-modified bitumen binders. For evaluating the engineering properties of the plastic-modified asphalt mixtures, the Marshall stability, Marshall flow, Marshall quotient and rutting tests were conducted. The results demonstrated that $6-8 \%$ is the ideal percentage of waste plastic proposed to amend and enhance the stiffness and elasticity behaviour of asphalt binders. Furthermore, the $8 \%$ waste PET-modified asphalt mixture showed the most improvement in stability and rutting resistance, as indicated by increased Marshal stability, increased Marshall quotient and decreased rut depth. Future fatigue and modulus stiffness tests on waste plastic-modified asphalt mixtures are suggested to further investigate the mechanical properties.
\end{abstract}

Keywords: asphalt; waste plastic; visco-elastic properties; Marshall stability; rutting resistance; environmental impact

\section{Introduction}

Rapid economic and industrial growth has increased Australia's waste production. In an attempt to manage these wastes and reduce their impact on the environment, different research projects have been conducted at Curtin University, Western Australia. These projects were focused on using waste materials to improve the building materials industry [1-3]. Results from these projects have shown the significance of utilising waste materials in building work and, in particular, improving geotechnical solutions and asphalt pavement reinforcement.

On the 1 January 2018, China enforced a ban on importing plastic waste, followed by similar prohibitions in other countries, such as India and Malaysia. These bans have had a significant impact on Australia's waste recycling industry $[4,5]$. The report stated that during 2018, the annual consumption of plastic was over three million tonnes, with only $9 \%$ recycled. It can be seen that during the last 17 years, Australia faced an extraordinary increase in waste materials as a result of people's daily lifestyle demands [4]. The consequent plastic waste produced has increased hazards and pollution [4,5]. As a result, the recycling of plastic waste in an environmentally friendly method is of great interest.

Using waste materials instead of new materials in the construction of roads has two significant benefits: substantially reduced costs and reduced waste going to landfill. Along 
with the importance of these benefits, the future development of using waste plastic in bitumen modification must consider how it enhances the properties of the mixture [6-9]. The current paper and another published paper [9] both belong one big project of using domestic waste plastic in the improvement of roads in WA, Australia. The published paper is different from the current submitted paper, because it only focused on binder properties in short- and long-term aging using the pressure aging vessel (PAV) method. Plastic has long been used in the asphalt industry showing competitive properties with commercial elastomer polymers in terms of improving engineering properties, such as rutting resistance and stiffness properties [10-13].

However, the addition of waste inclusions like PET would possibly lead to heterogeneous binders with brittle characteristics and low resistance to thermal and fatigue cracking. Previous studies focus on virgin plastic polymers and pay less attention to recycled plastics. Other studies [14-16] have displayed positive results using plastic in asphalt modification; nevertheless, few argue the use of a significant amount of plastics, such as PET and highdensity polyethylene (HDPE), for improving the mechanical properties and durability of modified asphalt. Durability is the ability to resist deformation in the long-term service of asphalt life. Of interest, these studies [11-16] reported that adding plastic polymers could notably improve rutting resistance $[15,16]$. Studies also confirmed that adding plastic enhanced the workability and stability of the mixture $[13,14,16]$. Further studies have indicated that using waste plastic also results in improved rutting resistance of asphalt mixtures [16-18].

According to previous studies [12,17-20], a waste plastic content of $4 \%$ is suggested as the ideal in asphalt to achieve good properties in term of strength, stability, stiffness, better durability and rutting resistance. On the other hand, studies by [21-24] suggested $6 \%$ waste plastic content is essential for an enhanced modifier that could increase the fatigue life and cracking resistance of asphalt. The application of recycled plastic to improve pavements ${ }^{\prime}$ properties has been carried out and evaluated in several countries, such as in the United Kingdom, Canada, India, the Netherlands and New Zealand, over the last seven years. In 2012, the city of Vancouver, Canada, used plastic waste as an alternative additive for reinforcing warm-mix asphalt [25]. As reported, three trail sections in Vancouver used local waste plastic in a $19 \mathrm{~mm}$ Superpave surface course warm-mix asphalt, thus helping to reduce the impact of greenhouse gases and improve air quality with $20 \%$ savings in energy used during mixing. Another example of the significance of utilising waste plastic in the pavement industry comes from the Netherlands in 2015 [26]. According to the construction company, a road fashioned out of recycled plastic would be able to resist low temperatures of $-40^{\circ} \mathrm{C}$ and up to highs of $80^{\circ} \mathrm{C}$, and be anti-corrosion and long-lasting for up to 50 years after construction [26].

According to investigations' reports [26-33], one of the effective ways of modifying asphalt is waste plastic, which would also be a way of supporting the environment and ecosystems. In addition, utilizing plastic polymers in asphalt potentially enhances the bitumen's temperature susceptibility and stiffness; this enhancement of bitumen results in an enhancement in the rutting and fatigue cracking resistance of asphalt pavement.

Lately, a valuable application of plastic waste has been tested in New Zealand to modify asphalt mixes [34]. According to their report, a large-scale trial of asphalt made with recycled plastic was conducted using 250 tonnes of plastic containers that would otherwise have been sent to landfill. Despite a few field trials in Brisbane, Melbourne and Sydney, since 2019 [35] no documented investigation has been reported in Australia. An earlier study by [35] was conducted using UK commercial plastic waste products added to C320 bitumen. Although some performance indicators were tested, the study [35] did not investigate the effect of local waste PET plastic on the elasticity and engineering properties of C320 asphalt using the wet-mix method. Consequently, there is a vital need to examine the performance of PET plastic-modified asphalt. This study aims to investigate and evaluate the impact of waste plastic in improving the engineering properties of asphalt 
mixes. The study will examine and evaluate the impact of waste plastic-modified asphalt on the enhancement of ageing stiffness performance and rutting resistance of the mixtures.

\section{Materials and Methods}

\subsection{Materials}

C320 bitumen binder was used in this study, supplied by SAMI Bitumen Technologies, Perth, Western Australia. Table 1 illustrates the physical properties of C320 bitumen. Local waste plastic bottles (PET) were collected, washed and used as a bitumen modifier after grinding to a size of $0.45 \mathrm{~mm}$. Figure 1 shows the materials used in this research study. Typical, $14 \mathrm{~mm}$, dense-graded asphalt for course surfacing was used. Granite aggregate was used, which is the most common natural aggregate in Western Australia. Table 2 displays the physical properties of the aggregate. Table 3 illustrates the particle size distribution of the aggregate.

Table 1. Physical properties of C320 binder.

\begin{tabular}{cccc}
\hline Property & Value & Units & Methods/Standards \\
\hline Viscosity at $60{ }^{\circ} \mathrm{C}$ & 320 & Pa.s & AS2 341.2 \\
Viscosity at $135^{\circ} \mathrm{C}$ & 0.5 & Pa.s & AS 2341.2 \\
Penetration at $25^{\circ} \mathrm{C}$ & 40 & $0.1 \mathrm{~mm}$ & AS 2341.12 \\
Flashpoint & 250 & ${ }^{\circ} \mathrm{C}$ & AS 2341.14 \\
\hline
\end{tabular}

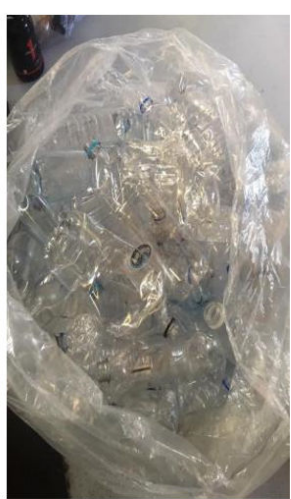

(A)

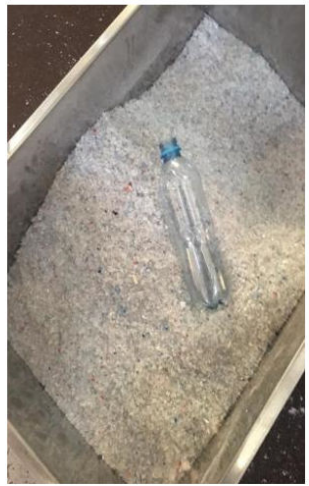

(B)

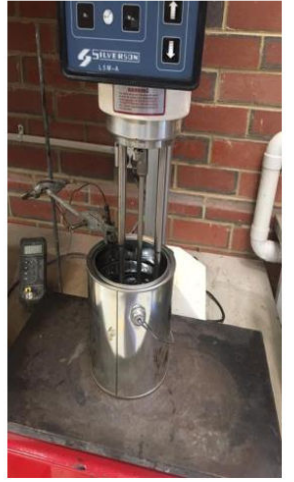

(C)

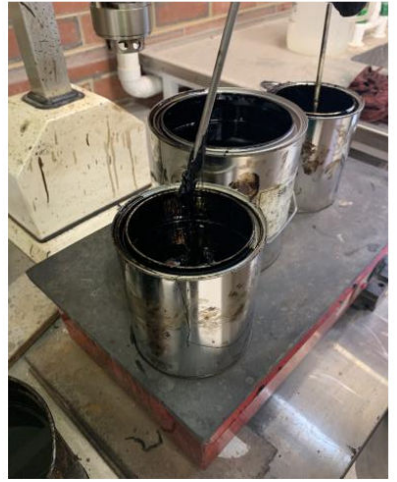

(D)

Figure 1. (A) Materials used in this research study of waste PET plastic; (B) plastic after grinding; (C) binder mixer using C320 bitumen; and (D) PET-modified C320 binders.

Table 2. Physical properties of the aggregate.

\begin{tabular}{ccc}
\hline Property of Course Aggregate & Standard & Value/Limits \\
\hline Water absorption $(\%)$ & AS 1141.6 .1 & $0.4<2$ \\
LA value $(\%)$ & AS 1141.23 & 24.3 \\
Aggregates crushed ACV (\%) & AS 1141.21 & 23.8 \\
Apparent particle density $\left(\mathrm{g} / \mathrm{cm}^{3}\right)$ & AS 1141.6 .1 & 2.692 \\
Particle density: A dry basis $\left(\mathrm{g} / \mathrm{cm}^{3}\right)$ & AS 1141.6 .1 & 2.663 \\
Particle density: A SSD basis $\left(\mathrm{g} / \mathrm{cm}^{3}\right)$ & AS1141.6.1 & 2.674 \\
\hline Property of fine aggregate & & \\
\hline Water absorption $(\%)$ & AS 1141.5 & 0.6 \\
Apparent particle density $\left(\mathrm{g} / \mathrm{cm}^{3}\right)$ & AS 1141.5 & 2.697 \\
Particle density: A dry basis $\left(\mathrm{g} / \mathrm{cm}^{3}\right)$ & AS 1141.5 & 2.633 \\
Particle density: A SSD basis $\left(\mathrm{g} / \mathrm{cm}^{3}\right)$ & AS1141.5 & 2.657 \\
\hline
\end{tabular}


Table 3. Particle size distribution of the aggregate.

\begin{tabular}{cccc}
\hline Sieve Size $(\mathbf{m m})$ & Lower Limit & Upper Limit & Selected Gradation \\
\hline 19 & 100 & 100 & 100 \\
13.2 & 90 & 100 & 93 \\
9.5 & 72 & 83 & 77 \\
6.7 & 54 & 71 & 62.5 \\
4.75 & 43 & 61 & 53.5 \\
2.36 & 28 & 45 & 35.5 \\
1.18 & 19 & 35 & 28.5 \\
0.6 & 13 & 27 & 20.5 \\
0.3 & 9 & 20 & 14 \\
0.15 & 6 & 13 & 8.5 \\
0.075 & 4 & 7 & 5 \\
\hline
\end{tabular}

\subsection{Samples Fabrication and Testing Methods}

Sample preparation was conducted in two stages: plastic-modified bitumen samples and plastic-modified asphalt mixture samples. In the first stage, a high shear mixer was used to prepare the samples of waste PET-modified bitumen containing $0 \%, 4 \%, 6 \%$ and $8 \%$ by weight of bitumen. After several trial mixes in a laboratory, the authors selected the ideal mix conditions of $180^{\circ} \mathrm{C}, 40 \mathrm{~min}$ and $2000 \mathrm{rpm}$ for temperature, time and mixing velocity, respectively. The DSR tests of modified and un-modified binders were carried out to determine the visco-elastic behaviour, stiffness and elasticity and to investigate the rutting resistance before and after ageing. To assess the temperature susceptibility of the waste plastic-modified binder, a broad range of temperatures, of $50^{\circ} \mathrm{C}, 58^{\circ} \mathrm{C}, 60^{\circ} \mathrm{C}, 64^{\circ} \mathrm{C}$ and $70^{\circ} \mathrm{C}$, were assessed and recorded.

The second stage was to add the plastic-modified bitumen into the aggregate to prepare the plastic-asphalt mixtures by following the wet-mix method, and using the Marshall method. An optimum binder content of 4.9 was used in samples of plastic-modified asphalt with a plastic content of $4-8 \%$ by weight of mixes. In addition, $1.5 \%$ hydrated lime by weight of dry aggregate was used as the recommended filler by the Main Roads Western Australia (MRWA) standard. Marshall test (AS 2891.5-2004) stability, Marshall flow, Marshall quotient and wheel-tracking tests (AGP-T054-15) were conducted to better understand the impact of plastic on the performance properties of asphalt mixtures.

\section{Results and Discussion}

\subsection{Results of Rheological Properties of Plastic-Modified Bitumen (before Ageing)}

To assess the rutting resistance of the asphalt binders, the DSR test was conducted. According to the test results, all modified samples had acceptable and satisfactory values. As can be seen in Figures 2 and 3, waste PET-modified asphalt samples show large values of phase angle and complex shear modulus in comparison to the C 320 binders (un-modified binders). In the specific high temperature range up to $70^{\circ} \mathrm{C}$, PET-modified asphalt samples showed an obvious improvement in terms of rutting resistance. The modified binder became less susceptible to deformation and, as such, improved the rutting resistance. The improvement in rutting resistance of the PET-modified samples through the different test temperatures showed better stiffness and elasticity performance in the modified samples. The results in Figures 2 and 3 display a better complex shear modulus and phase angle, which argues that PET particles integrate into asphaltenes, resulting in the swelling of the modified asphalt; this, in turn, leads to a significant improvement in binder viscosity and workability. This phenomenon indicates that the integration of the PET-asphalt blend leads to an improvement in elastic properties and is possibly associated with the characteristics and swelling of PET in the asphalt binder $[6,8,36]$. 


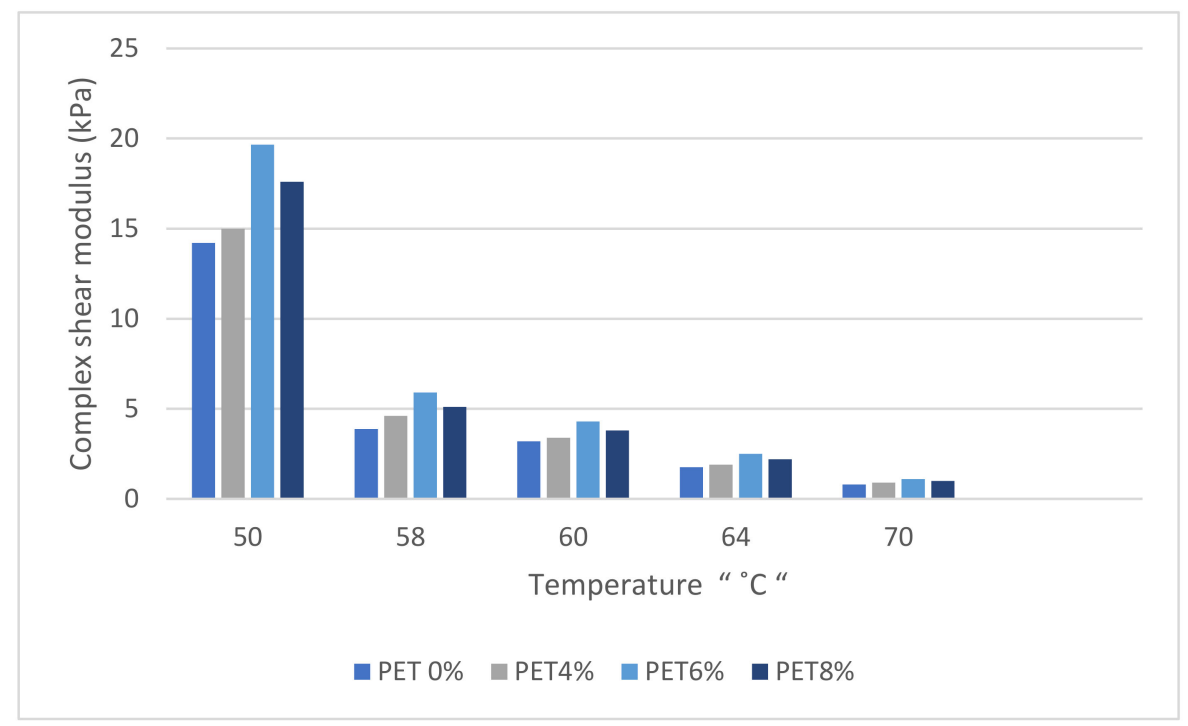

Figure 2. Complex shear modulus results of unaged PET-modified binders.

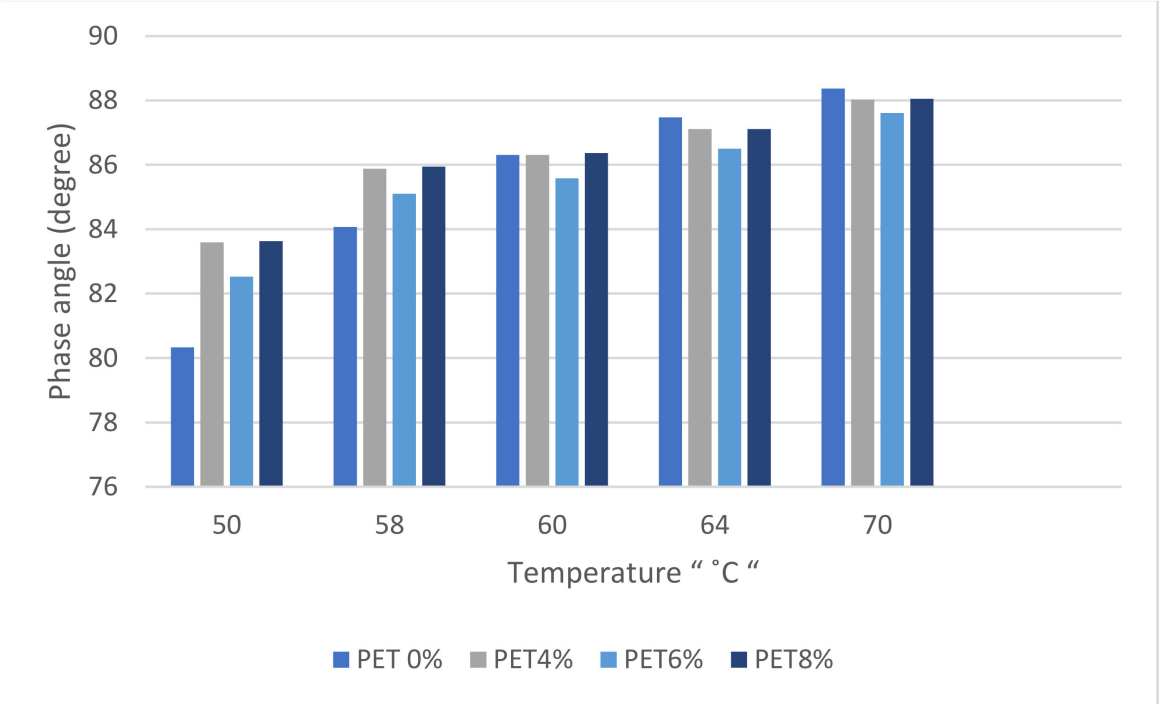

Figure 3. Phase angle results of unaged binders.

\subsection{Results of Rheological Properties in Plastic-Modified Bitumen after RTFOT Ageing}

Figures 4 and 5 show the impact of various PET contents on the visco-elastic behaviour of asphalt binders after RTFOT ageing. The DSR test assesses the visco-elastic properties, in terms of complex shear modulus and phase angle, through different testing temperatures from $50{ }^{\circ} \mathrm{C}$ to $70{ }^{\circ} \mathrm{C}$. At all testing temperatures, the complex shear modulus and phase angle samples improved, as shown in Figures 4 and 5. The results demonstrate that the addition of PET into asphalt improves stiffness, giving better durability and ageing-resistance. This tendency was confirmed through the phase angle values, as shown in Figure 5. There was a noticeable decrease in the phase angle of the $6-8 \%$ PET-modified bitumen samples as compared to un-modified samples (C320 bitumen). This, in turn, indicates successful improvement of elasticity of the modified bitumen binder. As a consequence, the rutting resistance of PET-modified bitumen samples would be increased. As can be seen from Figures 4 and 5, the PET-modified binders would have less thermo-oxidative ageing compared to un-modified binders. In addition, modified binders show less hardening behaviour, better bitumen-aggregate bonding and thus, better resistance to deformation and cracking $[8,35,36]$. 


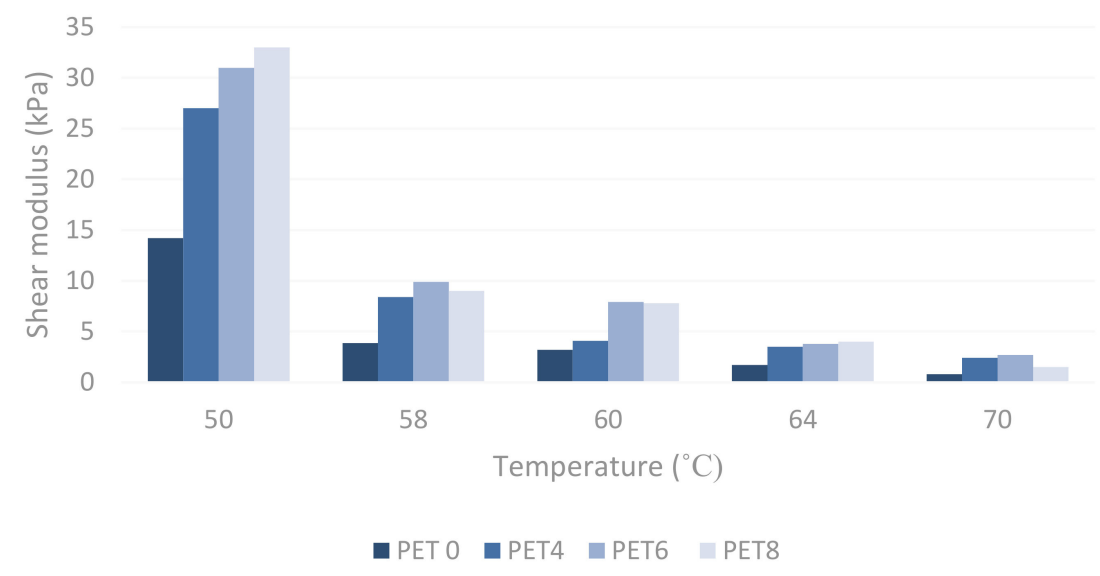

Figure 4. Complex shear modulus results of PET-modified binders after RTFOT.

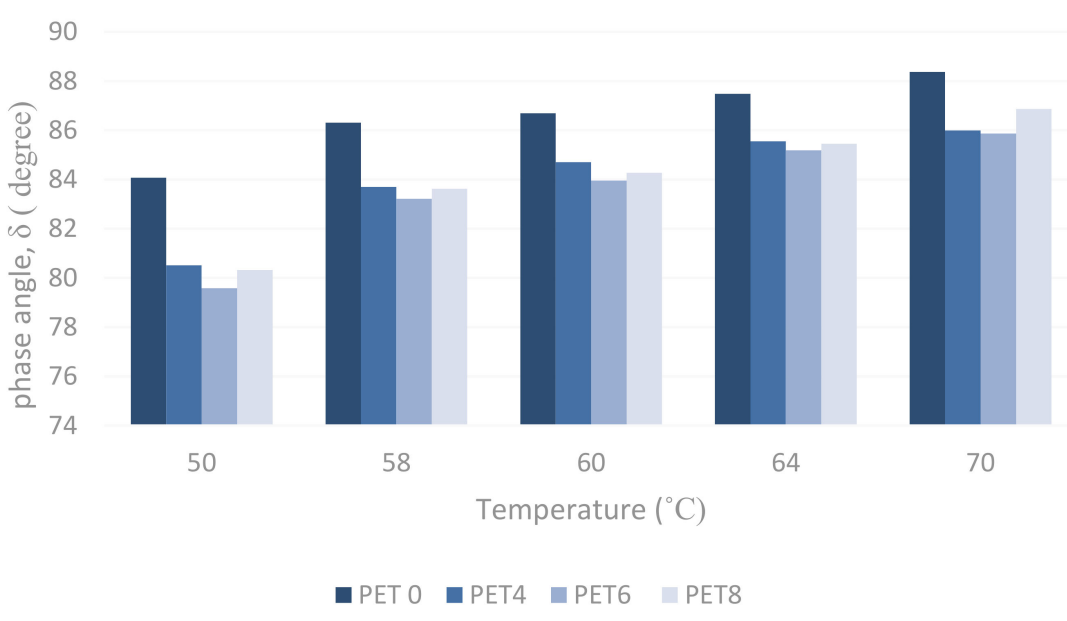

Figure 5. Phase angle results of PET-modified binders after RTFOT.

\subsection{Marshall Test Results}

The Marshall tests were simply conducted to investigate the ability of asphalt to withstand failure and rutting deformation under a substantial load of traffic. The values of Marshall stability, Marshal flow and Marshall quotient are displayed in Figures 6-8, respectively. As can be seen from Figure 6, the more waste plastic in the mixture, the higher the stability; therefore, the plastic-modified asphalt mixtures show better stability compared to the control mixture. The Marshall stability test is a well-known indicator of the resistance of bitumen materials to distortion, displacement, rutting and shear stress deformation [37]. The addition of plastic does result in a decrease in Marshall flow, as shown in Figure 7.

The Marshall quotient, referring to the ratio of Marshall stability to Marshall flow, can be used as a rutting resistance indicator; the results show that 6-8\% PET plastic significantly increases the modified mixture's resistance to deformation. Consequently, the waste plastic polymer increases the asphalt's Marshall stability; however, it also shows a significant negative impact on Marshall flow, these results being similar to previous findings [23,35]. As can be seen in Figures 6 and 8, the increase in Marshall stability and Marshall quotient of the plastic-modified asphalt could be related to the greater dispersion of the PET in the bitumen during shear mixing, which could confer greater stiffness and result in higher stability. The higher Marshall quotient (MQ) values indicate the plastic-modified asphalt has become stiffer, and indicates that the modified asphalt is more resistant to permanent deformation [17]. The Marshall properties are considered direct indicators of pavement 
performance [35]; higher stability and lower flow are associated with better pavement performance. From the above results, we can expect that the asphalt mixtures modified with waste plastic would have improved performance properties. Figures 6-8 show higher correlation factors of $R^{2}=0.985, R^{2}=0.979$ and $R^{2}=0.988$ for stability, flow and $M Q$, respectively.

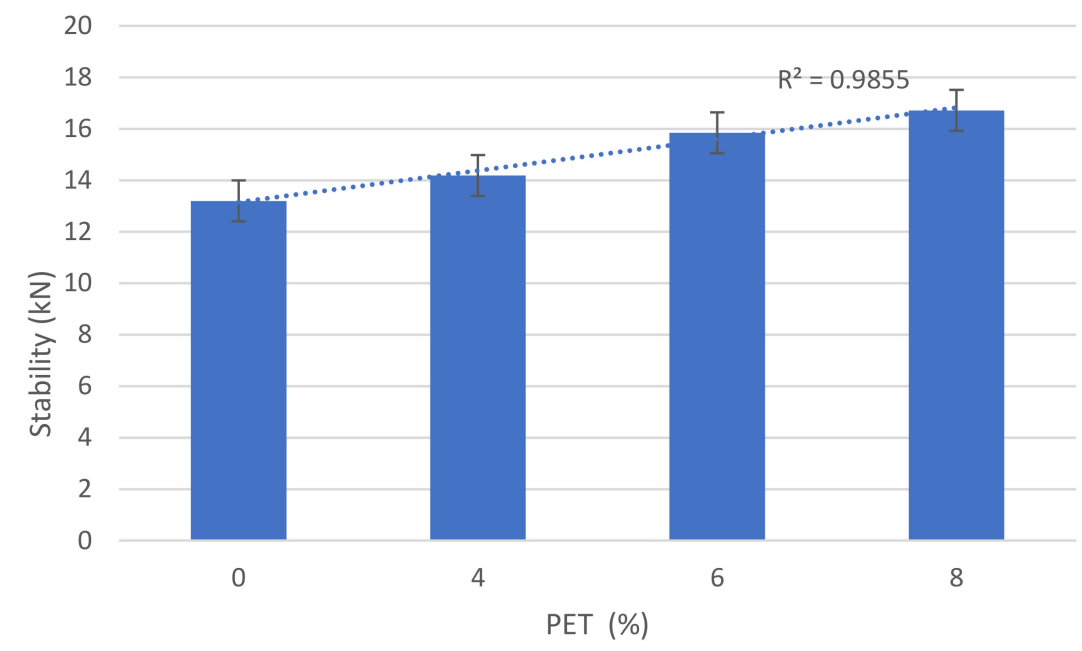

Figure 6. Marshall stability results.

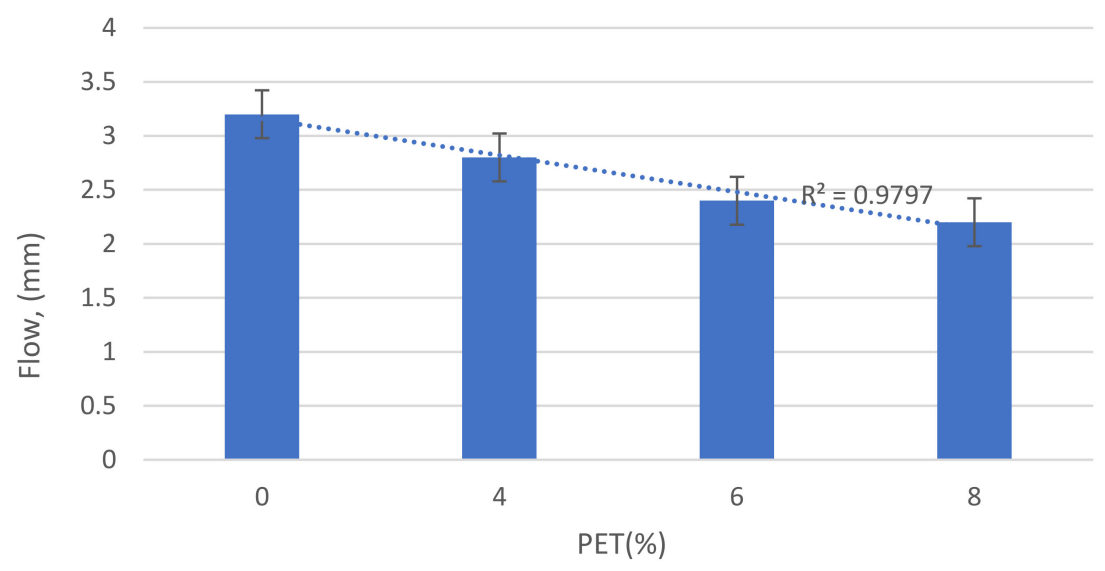

Figure 7. Marshall flow results.

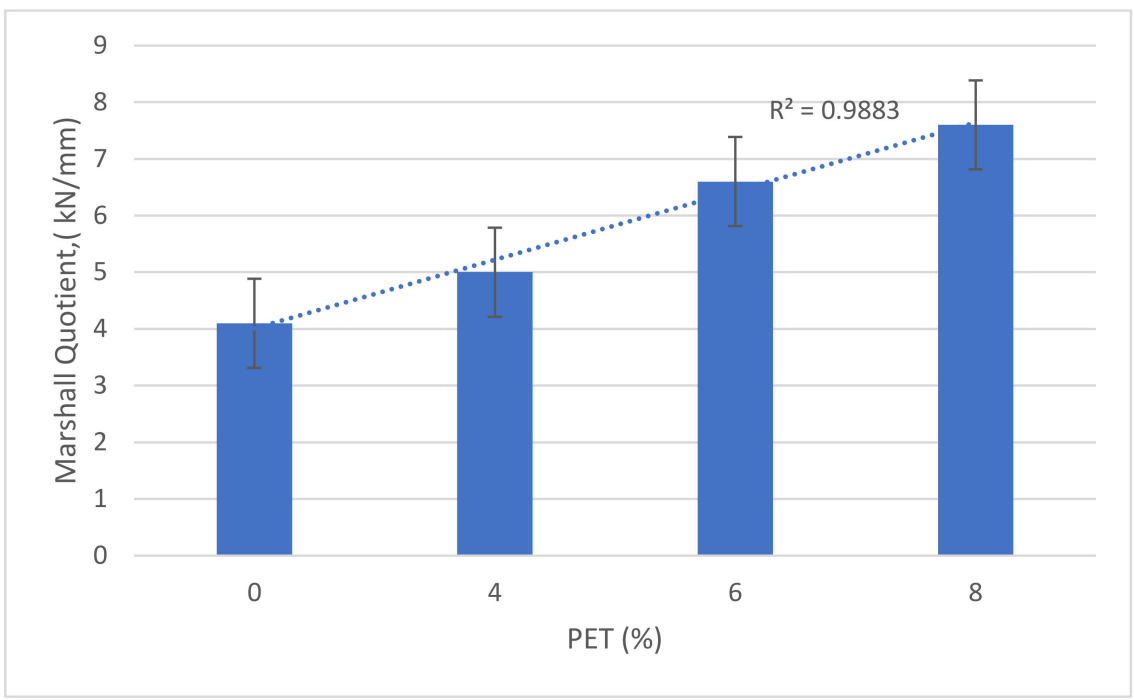

Figure 8. Marshall quotient results. 


\subsection{Wheel Tracking Tests Results}

Rutting is one of the main distresses impacting road surfaces, especially in hot climates. Since rutting deformation is linked to the asphalt binder sensitivity to stresses and temperatures when using modified binders $[9,21]$, it is vital to investigate the impact of the modified asphalt to clarify rutting resistance. The data of rutting tests used were the mean average of three readings for each PET content. As shown in Figure 9, the 4-8\% waste-PET plastic modification reduced the rut depth of the modified mixtures compared to un-modified C320 (0\% PET). The average rut depth of PET at 4,6 and $8 \%$ was $8.82 \mathrm{~mm}$, $5.59 \mathrm{~mm}$ and $3.25 \mathrm{~mm}$, respectively. These results indicate that waste plastic would enhance the mixture's deformation resistance. The diversity of physical and chemical properties of PET plastic and C320 asphalt might justify the results of Figure 9. Specifically, the chemical properties are affected during the blending process of plastic-bitumen using the high shear mixer, which would lead to changes in the particle dimensions of PET plasticbitumen-binders. Therefore, the engineering properties of PET-modified asphalt would be reinforced and improved in terms of elasticity increases. The increase in elasticity is due to the grouping of molecules and their bonds with each other [21,23]. Consequently, the waste PET-modified binders have the ability to improve the rutting resistance of pavements during their construction life and could be an effective additive in terms of reducing the costs of construction and maintenance.

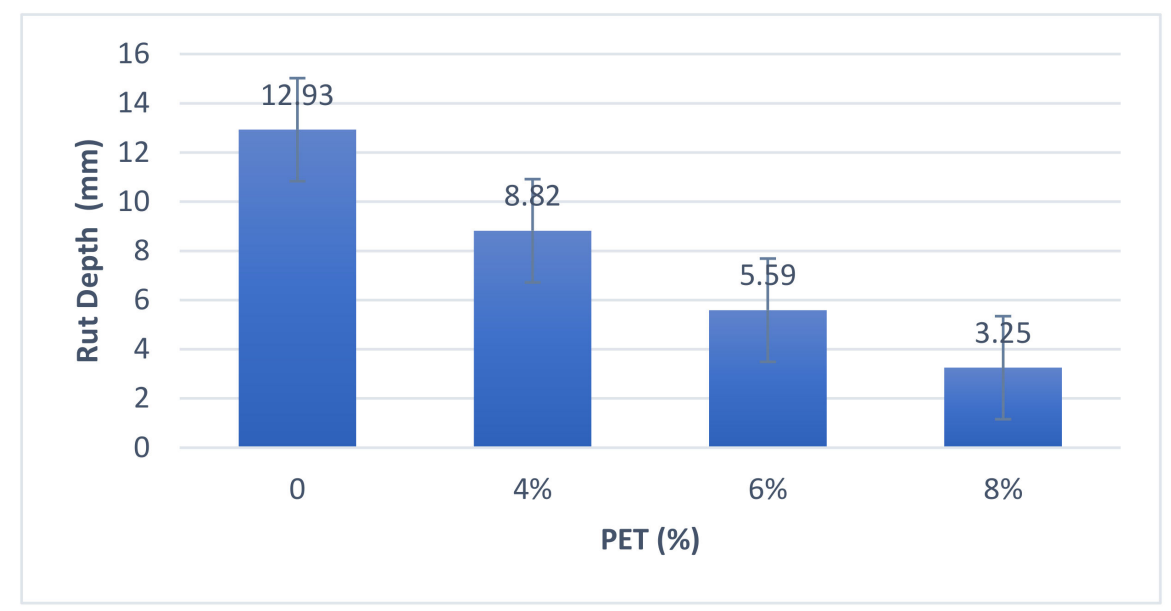

Figure 9. Rutting results vs. PET plastic content.

\section{Conclusions}

Bituminous pavements are vulnerable to cracking and rutting with certain temperature fluctuations; low temperatures can result in cracking; medium temperatures impose fatigue; and high temperatures result in a rutting problem. In line with such facts, changing and modifying the composition phase can enhance the engineering properties of the bituminous mixture through the injection of different additives. In the current study, waste plastic is used as a recycled additive to improve the engineering properties of bituminous mixtures through modification of the bitumen binder in the mix. Based on the current study, the notable findings are as below:

1. The study shows a promising and innovative approach of using local waste PET plastic as a modifier in C320 bitumen and asphalt mixtures.

2. According to the DSR results, samples of PET-modified asphalt indicate better performance in term of decreasing the asphalt's susceptibility to deformation at high temperatures, which would result in better rutting resistance. The complex shear modulus was increased and values of the phase angle reduced due to addition of PET to the binder. At the testing temperatures of $50-70{ }^{\circ} \mathrm{C}$, a better rutting resistance was achieved which can be attributed to the elasticity of materials. 
3. Based on short-term ageing (RTFOT) results, PET additives were less ageing, showed a higher complex shear modulus and had better elasticity with a better phase angle. These results indicate an ability to resist ageing during construction and offer better durability during long life service of asphalt pavement.

4. The waste PET-modified mixtures show good stiffness and improved stability, offering better resistance to shear stress under heavy loads. The values of the Marshall stability for all waste PET-modified asphalt mixtures were higher compared to the control mixture (C320); however, waste plastic had less impact on Marshall flow. The higher Marshall quotient (MQ) values indicate the plastic-modified asphalt became stiffer and indicates that the modified asphalt is more resistant to deformation.

5. The optimum content of waste plastic was $8 \%$, resulting in smaller rut depth and improved resistance of modified mixtures to rutting deformation. Further stiffness and fatigue tests on asphalt mixtures samples are recommended to better understand the mechanical properties of waste PET plastic on modified C320 asphalt mixtures. Future tests should conduct various mixing conditions and quantify the reinforcement capability of PET-modified asphalt mixtures. In addition, possible future works could include the evaluation of PET contents variations over time, including aging simulation, alternated with UV radiation.

Author Contributions: Conceptualization, N.M. and A.C.; methodology, N.M. and A.C.; validation, N.M., A.C. and H.N.; formal analysis, N.M.; investigation, N.M.; resources, N.M. and A.C.; data curation, N.M.; writing-original draft preparation, N.M.; writing-review and editing, N.M.; visualization, N.M.; project leader, A.C.; project administration, N.M., A.C. and H.N. All authors have read and agreed to the published version of the manuscript.

Funding: This research was funded by the Australian Government Research Training Program RTP. Institutional Review Board Statement: Not applicable.

Informed Consent Statement: Not applicable.

Data Availability Statement: The data presented in this study are available on request from the corresponding author.

Acknowledgments: Authors would like to acknowledge the contribution of the Australian Government Research Training Program RTP in supporting this research project.

Conflicts of Interest: The authors declare no conflict of interest.

Sample Availability: Not available.

\section{References}

1. Chegenizadeh, A.; Keramatikerman, M.; Panizza, S.; Nikraz, H. Effect of powder recycled tire on sulfate resistance of cemented clay. J. Mater. Civ. Eng. 2017, 29, 04017160. [CrossRef]

2. Chegenizadeh, A.; Keramatikerman, M.; Santa, G.D.; Nikraz, H. Influence of recycled tyre amendment on the mechanical behavior of soil-bentonite cut-off walls. J. Clean. Prod. 2018, 177, 507-515. [CrossRef]

3. Piromanski, B.; Chegenizadeh, A.; Mashaan, N.; Nikraz, H. Study on HDPE effect on rutting resistance of binder. Buildings 2020, 10, 156. [CrossRef]

4. $\quad$ O' Farrell, K. 2017-2018 Australian Plastics Recycling Survey, National Report; Project Reference A21505; Australian Government: Canberra, Australia, 2019.

5. Chin, C.; Damen, P. Viability of Using Recycled Plastics in Asphalt and Sprayed Sealing Applications; Technical Report No. AP-T351-19; Austroad Ltd.: Sydney, Australia, 2019; ISBN 978-1-925854-51-0.

6. Dalhat, M.A.; Al-Abdul Wahhab, H.I. Performance of recycled plastic waste modified asphalt binder in Saudi Arabia. Int. J. Pavement Eng. 2017, 18, 349-357. [CrossRef]

7. Hamedi, G.H.; Hadizadeh Pirbasti, M.; Ranjbar Pirbasti, Z. Investigating the effect of using waste ultra-high-molecular-weight polyethylene on the fatigue life of asphalt mixture. Period. Polytech. Civ. Eng. 2020, 64, 1170-1180.

8. White, G. A Synthesis on the Effects of Two Commercial Recycled Plastics on the Properties of Bitumen and Asphalt. Sustainability 2020, 12, 8594. [CrossRef]

9. Mashaan, N.S.; Chegenizadeh, A.; Nikraz, H.; Rezagholilou, A. Investigating the engineering properties of asphalt binder modified with waste plastic polymer. Ain Shams Eng. J. 2021, 12, 1569-1574. [CrossRef] 
10. Al-Hadidy, A.; Yi-Qui, T. Effect of polyethylene on life of flexible pavements. Constr. Build. Mater. 2009, 23, 1456-1464. [CrossRef]

11. Al-Hadidy, A.; Yi-Qiu, T. Mechanistic approach for polypropylene-modified flexible pavements. Mater. Des. 2009, 30, 1133-1140. [CrossRef]

12. Awwad, M.; Shbeeb, L. The use of polyethylene in hot asphalt mixtures. Am. J. Appl. Sci. 2007, 4, 390-396. [CrossRef]

13. Attaelmanan, M.; Feng, C.P.; Al-Hadidy, A. laboratory evaluation of HMA with high density polyethylene as a modifier. Constr. Build. Mater. 2011, 25, 2764-2770. [CrossRef]

14. Vansudevan, R.; Sekar, A.R.C.; Sundarakannan, B.; Velkennedy, R. A technique to dispose waste plastics in an ecofriendly way-Application in construction of flexible pavement. Constr. Build. Mater. 2012, 28, 311-320. [CrossRef]

15. Mahdi, F.; Khan, A.A.; Abbas, H. Physiochemical properties of polymer mortar composites using resins derived from postconsumer PET bottles. Cem. Concr. Compos. 2007, 29, 241-248. [CrossRef]

16. Costa, L.M.; Silva, H.M.; Peralta, J.; Oliveira, J.R. Using waste polymers as a reliable alternative for asphalt binder modificationPerformance and morphological assessment. Constr. Build. Mater. 2019, 198, 237-244. [CrossRef]

17. Hınıslıŏlu, S.; Ağar, E. Use of waste high density polyethylene as bitumen modifier in asphalt concrete mix. Mater. Lett. 2004, 58, 267-271. [CrossRef]

18. Casey, D.; McNally, C.; Gibney, A.; Gilchrist, M.D. Development of a recycled polymer modified binder for use in stone mastic asphalt. Resour. Conserv. Recycl. 2008, 52, 1167-1174. [CrossRef]

19. Ahmad, L.A. Improvement of Marshall properties of the asphalt concrete mixtures using the polyethylene as additive. Eng. Technol. 2007, 25, 383-394.

20. Sara, F.; Silva, H.M.; Oliveira, J.R. Mechanical, surface and environmental evaluation of stone mastic asphalt mixtures with advanced asphalt binders using waste materials. Road Mater. Pavement Des. 2017, 20, 316-333.

21. Ameri, M.; Nasri, D. Perfromance properties of devulcanized waste PET modified asphalt mixtures. Pet. Sci. Technol. 2017, 35, 99-104. [CrossRef]

22. Yu, B.; Jiao, L.; Ni, F.; Yang, J. Evaluation of plastic-rubber asphalt: Engineering property and environmental concern. Constr. Build. Mater. 2014, 71, 416-424. [CrossRef]

23. Sojobi, A.O.; Nwobodo, S.E.; Aladegboye, O.J. Recycling of polyethylene terephthalate (PET) plastic bottle wastes in bituminous asphaltic concrete. Cognet Eng. 2016, 3, 1133480. [CrossRef]

24. Khan, I.M.; Kabir, S.; Alhussain, M.A.; Almansoor, F.F. Asphalt design using recycled plastic and crumb-rubber waste for sustainable pavement construction. Procedia Eng. 2016, 145, 1557-1564. [CrossRef]

25. Ridden, P. The Streets of Vancouver Are Paved with Recycled Plastic; New Atlas: Vancouver, Canada, 2012. Available online: http:/ / newatlas.com/vancouver-recycled-plastic-warm-mix-asphalt/25254/ (accessed on 20 October 2020).

26. Saini, S. Forget Asphalt: A European City Is Building a Road Made Entirely out of Recycled Plastic; Business Insider: Amsterdam, The Netherlands, 2015. Available online: https://sg.finance.yahoo.com/news/forget-asphalt-european-city-building-163000280. $\mathrm{html}$ (accessed on 20 October 2020).

27. Li, R.; Leng, Z.; Yang, J.; Lu, G.; Huang, M.; Lan, J.; Zhang, H.; Bai, Y.; Dong, Z. Innovative application of waste polyethylene terephthalate (PET) derived additive as an antistripping agent for asphalt mixture: Experimental investigation and molecular dynamics simulation. Fuel 2021, 300, 121015. [CrossRef]

28. Esfandabad, A.S.; Motevalizadeh, S.M.; Sedghi, R.; Ayar, P.; Asgharzadeh, S.M. Fracture and mechanical properties of asphalt mixtures containing granular polyethylene terephthalate (PET). Constr. Build. Mater. 2020, 259, 120410. [CrossRef]

29. Ghabchi, R.; Dharmarathna, C.P.; Mihandoust, M. Feasibility of using micronized recycled Polyethylene Terephthalate (PET) as an asphalt binder additive: A laboratory study. Constr. Build. Mater. 2021, 292, 123377. [CrossRef]

30. Nizamuddin, S.; Jamal, M.; Santos, J.; Giustozzi, F. Recycling of low-value packaging films in bitumen blends: A grey-based multi criteria decision making approach considering a set of laboratory performance and environmental impact indicators. Sci. Total. Environ. 2021, 778, 146187. [CrossRef]

31. Nizamuddin, S.; Jamal, M.; Gravina, R.; Giustozzi, F. Recycled plastic as bitumen modifier: The role of recycled linear low-density polyethylene in the modification of physical, chemical and rheological properties of bitumen. J. Clean. Prod. 2020, 266, 121988. [CrossRef]

32. BintiJoohari, I.; Giustozzi, F. Chemical and high-temperature rheological properties of recycled plastics-polymer modified hybrid bitumen. J. Clean. Prod. 2020, 276, 123064.

33. Santos, J.; Pham, A.; Stasinopou, P.; Giustozzi, F. Recycling waste plastics in roads: A life-cycle assessment study using primary data. Sci. Total. Environ. 2021, 751, 141842. [CrossRef]

34. Parkes, R. Recycled Plastic Used in Airport Asphalt; Roads \& Infrastructure Australia: Christchurch New Zealand 2018. Available online: http:/ / roadsonline.com.au/recycled-plasticused-in-airport-asphalt/ (accessed on 20 October 2020).

35. White, G.; Magee, C. Laboratory Evaluation of Asphalt Containing Recycled Plastic as a Bitumen Extender and Modifier. J. Traffic Transp. Eng. 2019, 7, 218-235.

36. Leng, Z.; Sreeram, A.; Padhan, R.K.; Zhifei, T. Value-Added Application of Waste Pet Based Additives in Bituminous Mixtures Containing High Percentage of Reclaimed Asphalt Pavement (Rap). J. Clean. Prod. 2018, 196, 615-625. [CrossRef]

37. Mashaan, N.; Ali, A.H.; Koting, S.; Karim, M.R. Performance Evaluation of Crumb Rubber Modified Stone Mastic Asphalt Pavement in Malaysia. Adv. Mater. Sci. Eng. 2013, 2013, 304676. [CrossRef] 